\title{
GCU
}

Glasgow Caledonian

University

University for the Common Good

\section{Steady-state analysis of full-bridge series resonant converter with phase-shift and frequency control}

Aboushady, Ahmed; Ahmed, Khaled; Finney, Stephen; Williams, Barry

Published in:

5th IET International Conference on Power Electronics, Machines and Drives (PEMD 2010)

DOI:

10.1049/cp.2010.0032

Publication date:

2010

Document Version

Author accepted manuscript

Link to publication in ResearchOnline

Citation for published version (Harvard):

Aboushady, A, Ahmed, K, Finney, S \& Williams, B 2010, Steady-state analysis of full-bridge series resonant converter with phase-shift and frequency control. in 5th IET International Conference on Power Electronics, Machines and Drives (PEMD 2010). Institution of Engineering and Technology (IET).

https://doi.org/10.1049/cp.2010.0032

\section{General rights}

Copyright and moral rights for the publications made accessible in the public portal are retained by the authors and/or other copyright owners and it is a condition of accessing publications that users recognise and abide by the legal requirements associated with these rights.

Take down policy

If you believe that this document breaches copyright please view our takedown policy at https://edshare.gcu.ac.uk/id/eprint/5179 for details

of how to contact us. 


\title{
STEADY-STATE ANALYSIS OF FULL-BRIDGE SERIES RESONANT CONVERTER WITH PHASE-SHIFT AND FREQUENCY CONTROL
}

\author{
A.A.Aboushady, K.H.Ahmed, S.J.Finney, B.W.Williams \\ Department of Electronic and Electrical Engineering \\ Strathclyde University, Glasgow, UK \\ E-mail: ahmed.aboushady@eee.strath.ac.uk
}

Keywords: Series Resonant Converter (SRC), Phase-shift (PS), Steady-state ac analysis, frequency control.

\begin{abstract}
This paper presents steady-state ac analysis of the series resonant converter with phase-shift and frequency control. Analysis for the converter operation above resonance is performed. A simple analytical expression for the converter input/output voltage gain as a function of phase-shift and frequency is derived. Different converter operation modes are demonstrated with simulation results. Analytical expressions for mode boundaries and maximum power transfer to load are derived, discussed, and graphically represented.
\end{abstract}

\section{Introduction}

Resonant converters have lower switching losses and switching stresses compared to conventional hard-switched PWM converters, and therefore can be operated at higher frequencies. This makes them feasible for modular power supplies with high power/size ratios. The series resonant converter (SRC), considered for analysis in this paper, uses minimum components for a basic step-down isolated resonant power supply. Various control techniques have been applied to SRCs in the literature. These include average current control [1], frequency control [2], capacitor voltage control [3], diode conduction angle control [4], optimal trajectory control monitoring the energy level of the resonant tank $[5,6]$ and pulse density modulation [7-9]. These methods were mainly applied to half-bridge SRC topologies. Phase-shift modulation [10-14] has been applied to full-bridge SRCs. Various steady-state models with rigorous mathematical analysis, have been derived for half and full-bridge SRCs [1518]. Such models have not investigated the effect of phaseshift control. However, steady-state performance analysis of phase-shifted SRCs in [10] provides insight but has no detailed analytical expressions.

This paper proposes simple analytical equations to study the steady-state performance of the full-bridge phase-shifted SRCs. The paper is organized as follows. Section one is an introduction providing literature review about SRC with the different control techniques used and steady-state models previously proposed. Section two presents the SRC basic circuit description and nomenclature. In section three, a generalized input/output voltage gain transfer function is derived for the SRC as a function of phase-shift and frequency. In section four, converter modes of operation are discussed in detail with simulation results illustrating each and verifying the derived gain transfer function. Mode boundaries and conditions for maximum power transfer to the load are derived, analyzed graphically and discussed in section five.

\section{Basic circuit description}

\subsection{Nomenclature}

Figure 1 illustrates the full-bridge SRC topology. This configuration can be simplified into the equivalent circuit in figure 2. All variables used are summarised and defined in Table 1. The full-bridge inverter feeds a series resonant tank. The tank current is rectified and filtered using a capacitive filter to produce the required dc voltage at output. Control is achieved via frequency and phase-shift control, where the frequency of inverter output is varied in addition to effective duty ratio. Inverter switches are on for $50 \%$ of switching period and the effective duty ratio is changed by controlling the phase-shift between the two inverter legs. The phase-shift control procedure is illustrated in figure 3.

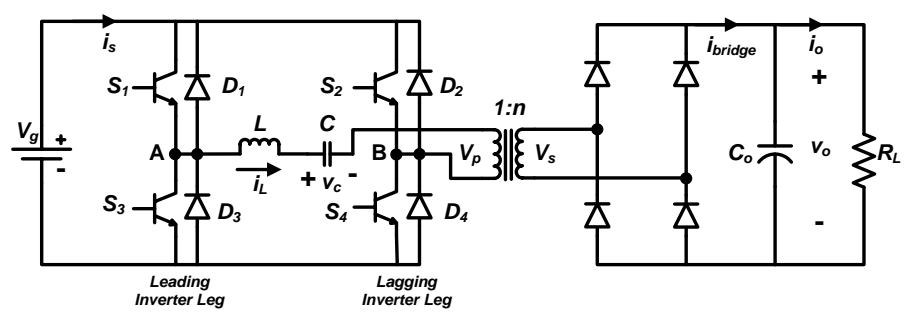

Figure 1: Full-bridge phase-shifted SRC converter topology.

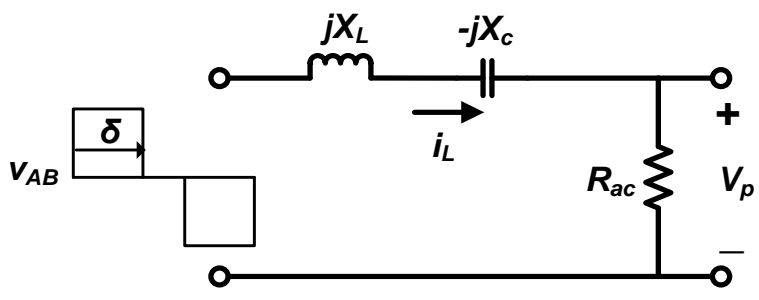

Figure 2: AC equivalent circuit of full-bridge phase-shifted SRC. 


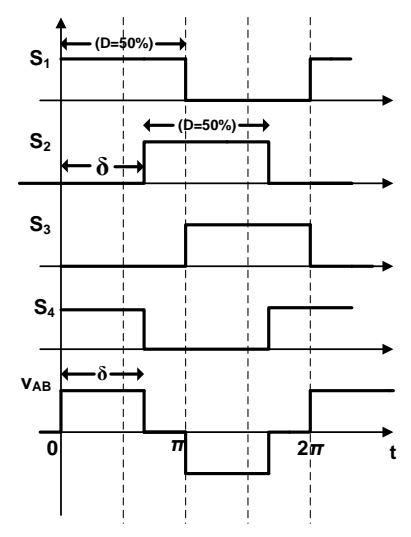

Figure 3: Gating technique for phase-shift modulation.

\begin{tabular}{|l|l|}
\hline $\boldsymbol{v}_{\boldsymbol{g}}$ & DC supply voltage (V) \\
\hline $\boldsymbol{v}_{\boldsymbol{A} \boldsymbol{B}}$ & Inverter output voltage (V) \\
\hline $\boldsymbol{i}_{\boldsymbol{L}}$ & Resonant tank inductor current (A) \\
\hline $\boldsymbol{v}_{\boldsymbol{c}}$ & Resonant tank capacitor voltage (V) \\
\hline $\boldsymbol{i}_{\boldsymbol{s}}$ & DC supply current (A) \\
\hline $\boldsymbol{v}_{\boldsymbol{p}}$ & Transformer primary voltage (V) \\
\hline $\boldsymbol{v}_{\boldsymbol{s}}$ & Transformer secondary voltage (V) \\
\hline $\boldsymbol{n}$ & Resonant tank inductor $(\mu \mathrm{H})$ \\
\hline $\boldsymbol{L}$ & Resonant tank capacitor $(\mu \mathrm{F})$ \\
\hline $\boldsymbol{C}$ & Output filter capacitance $(\mu \mathrm{F})$ \\
\hline $\boldsymbol{C}_{\boldsymbol{o}}$ & Output voltage and current respectively $(\mathrm{V}, \mathrm{A})$ \\
\hline $\boldsymbol{v}_{\boldsymbol{o}}, \boldsymbol{i}_{\boldsymbol{o}}$ & Rectified bridge current $(\mathrm{A})$ \\
\hline $\boldsymbol{i}_{\boldsymbol{b r i d} \boldsymbol{e}}$ & Load resistance $(\Omega)$ \\
\hline $\boldsymbol{R}_{\boldsymbol{L}}$ & AC equivalent resistance of bridge rectifier $(\Omega)[19]$ \\
\hline $\boldsymbol{R}_{\boldsymbol{a c}}=\frac{\mathbf{8}}{\boldsymbol{\pi}^{\mathbf{2}}} \boldsymbol{R}_{\boldsymbol{L}}$ & $f_{S}=$ Inverter switching frequency $(\mathrm{kHz})$ \\
\hline $\boldsymbol{\omega}=\mathbf{2 \pi} \boldsymbol{f}_{\boldsymbol{s}}$ & $f_{o}=$ Resonant frequency $=1 / 2 \pi \sqrt{L C}(\mathrm{kHz})$ \\
\hline $\boldsymbol{\omega}_{\boldsymbol{o}}=\mathbf{2 \pi} \boldsymbol{f}_{\boldsymbol{o}}$ & Duty Ratio= $T_{O N} / T_{S}, D \leq 0.5$ \\
\hline $\boldsymbol{D}$ & Phase-shift angle (rad) $\delta \leq \pi$ \\
\hline $\boldsymbol{\delta}$ & Characteristic impedance $=\sqrt{L / C}(\Omega)$ \\
\hline $\boldsymbol{Z}_{\boldsymbol{o}}$ & Quality factor $=Z_{o} / R_{L}$ \\
\hline $\boldsymbol{Q}$ & \\
\hline
\end{tabular}

Table 1: Nomenclature.

\subsection{Assumptions}

The output capacitive filter is large enough to ensure constant output voltage at steady-state. For analysis simplicity, the transformer is considered with unity turns ratio and its leakage inductance is added to the resonant tank inductor. Analysis is carried out for operation above resonance. Advantages of such operation have been discussed thoroughly in literature. When operating above resonance [19], the impedance becomes inductive hence the inverter draws lagging current (with respect to fundamental inverter output voltage). This eliminates switch turn on losses as the load current is diverted to its inverse diode prior to transistor conduction; hence its voltage is zero at turn on. Diodes can be medium speed types. Nevertheless, the transistor must switch off current and is therefore subject to turn off losses. Lossless snubbers (pure capacitance) can be placed across the switching device to reduce the turn off losses. All of the aforementioned advantages are lost if the converter is operated below resonance. That is, below resonance operation results in transistor turn on switching losses, diode switching losses (high speed diodes are needed) and input/output filters must be designed for the minimum switching frequency.
Transistor turn off does occur in a lossless manner when operating below resonance. However, because turn off losses can be reduced using lossless snubbers when operating above resonance, this is not a major argument for operating below resonance.

\section{Voltage gain characteristics}

Implementing the ac equivalent circuit in figure 2, the ac gain of the SRC can be expressed using a voltage divider by

$$
\frac{\left|V_{P_{1}}\right|}{\left|V_{A B_{1}}\right|}=\frac{1}{\mid 1+j\left[\frac{X_{L}}{R_{a c}}-\frac{X_{C}}{R a c} \mid\right.}
$$

where, $V_{A B_{1}}$ and $V_{P_{1}}$ are the fundamental inverter output and transformer primary voltages respectively. According to figure 4, and assuming continuous and near sinusoidal inductor current $i_{L}(t)$, the Fourier transform is applied to obtain $\left|V_{A B_{1}}\right|$ and $\left|V_{P_{1}}\right|$

$$
\frac{\frac{4 V_{O}}{\pi}}{\frac{4 V g}{\pi} \sin \frac{\delta}{2}}=\frac{1}{\left|1+j\left[\frac{X_{L}}{R_{a c}}-\frac{X_{C}}{R_{a c}}\right]\right|}
$$

Utilising the definitions of $R_{a c}, Q$ and $\omega_{0}$ in Table 1, (2) can be expressed as

$$
M=\frac{V_{o}}{V_{g}}=\frac{\sin \frac{\delta}{2}}{\left|1+j \frac{\pi^{2}}{8} Q\left[\frac{\omega}{\omega_{0}}-\frac{\omega_{0}}{\omega}\right]\right|}
$$

where $M$ is the converter voltage gain. From (3), $M$ is a nonlinear function of $\delta, \omega$ and Q. Figure 5 illustrates this nonlinear relationship with simulation values summarised in Table 2. The figure shows that the converter

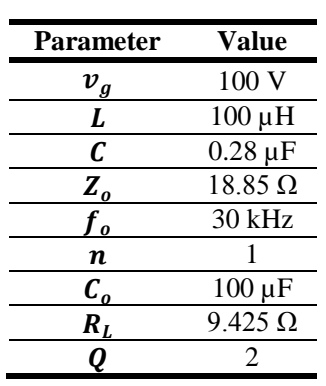

Table 2: Simulation values

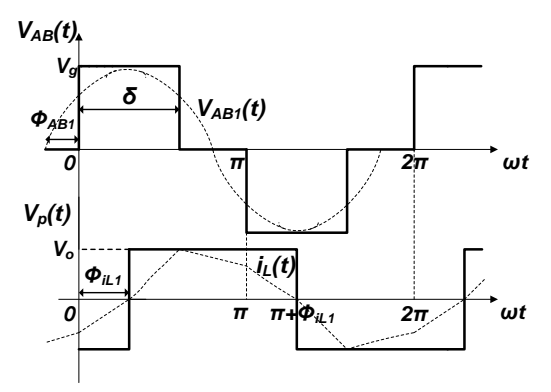

Figure 4: Output voltage waveforms.

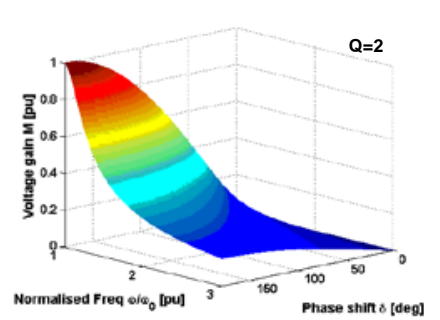

(a)

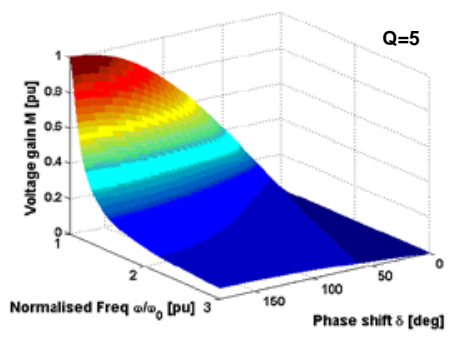

(b)
Figure 5: Converter Gain $M$ against phase-shift and frequency of operation (a) light load, (b) heavy load 
voltage gain increases with an increase in phase-shift and decreases the higher the resonant frequency is exceeded. The converter is more sensitive to a change in frequency at heavier loads which can be seen from the highly decaying slope of converter gain. Generally, for the same phase-shift and frequency, the converter has a lower gain at heavier loads.

\section{Modes of operation}

Three steady-state modes of operation exist for the phaseshifted SRC operating above resonance; two continuous current modes and one discontinuous mode.

\subsection{Mode 1 operation (Continuous inductor current with energy recovery to supply)}

Typical mode 1 waveforms are shown in figure 6 . Figure 7 shows the equivalent circuits for each of the positive half cycle sub-periods with the conducting devices in each subperiod. This can be verified from the gating sequence in figure 3. Negative half cycle equivalent circuits are identical but with $-v_{g}$ and complementary switches conducting. This is a continuous current mode of operation. From figure 6a, during sub-period $A$ inductor current is negative; hence, resonant tank energy is fed back to the dc supply through the free-wheel diodes $\mathrm{D}_{1} \mathrm{D}_{4}$. This characterizes mode 1 operation. At the end of sub-period $A$, the resonant inductor current falls to zero (energy in tank is dissipated/returned to supply). The powering stage starts with sub-period $B$ where energy is transferred from the source to the tank through the switches $\mathrm{S}_{1} \mathrm{~S}_{4}$. During sub-period $C$, the converter upper half conducts $\left(D_{2} S_{1}\right)$. Energy in the resonant tank is dissipated in the zero voltage loop and no energy is returned to supply during this time. Figure 6b, showing inverter switches voltage and current waveforms, verifies zero voltage turn-on for all four switches in this mode of operation. Load current is carried by the switch inverse diode prior to switch operation hence voltage across it is zero before conduction of forward current. All four switches turn off whilst conducting current. Such device stresses can be reduced by the use of lossless capacitive snubbers. The inverter leading leg switches turn off the current at $t=\frac{T_{S}}{2}$ whereas the inverter lagging leg switches turn off current at $t=t_{1}$. Switching stresses are, therefore, higher on the lagging leg compared to leading leg.

In order to verify the converter voltage gain formula in (3), simulation results in figure 6 are taken for $\delta=120^{\circ}, Q=2$, $f_{s}=40 \mathrm{kHz}$, and $v_{g}=100 \mathrm{~V}$. By substituting in (3), converter voltage gain is $M=0.494$ and thus, $v_{o} \simeq 50 \mathrm{~V}$. This value of $v_{o}$ can be verified from figure 6a since $v_{p} \simeq$ $\pm 49.4 \mathrm{~V}$. This validates the proposed converter gain formula.

The condition necessary for the existence of this mode is that the fundamental inductor current lags the $t=t_{0}$ instant by $\phi_{I_{L_{1}}}$ as shown in figure 6a. From figure 2, assuming sinusoidal inductor current and considering only fundamental components (higher harmonic impedances are large)

$$
\begin{array}{r}
\left|I_{L_{1}}\right|=\frac{\left|V_{A B_{1}}\right|}{\left|R_{a c}+j\left(X_{L}-X_{C}\right)\right|} \\
\phi_{I_{L_{1}}}=\phi_{V_{A B_{1}}}-\phi_{Z}
\end{array}
$$

where $\phi_{I_{L_{1}}}$ and $\phi_{V_{A B_{1}}}$ are the angles of fundamental inductor current and inverter output voltage respectively and $\phi_{Z}$ is the impedance angle. As from figure $4, \phi_{V_{A B_{1}}} \leq 0$ is due to the asymmetry of $v_{A B}$ and $\phi_{Z} \geq 0$ is due to the inductive nature of the resonant tank operating above resonance. Therefore, mode 1 condition can be derived as in (8)

$$
\begin{gathered}
-\phi_{V_{A B_{1}}}+\phi_{Z} \geq 0 \\
-\frac{\pi-\delta}{2}+\tan ^{-1} \frac{X_{L}-X_{C}}{R_{a c}} \geq 0 \\
\delta \geq \pi-2 \tan ^{-1} \frac{\pi^{2}}{8} Q\left[\frac{\omega}{\omega_{0}}-\frac{\omega_{0}}{\omega}\right]
\end{gathered}
$$

This shows that for operation at the resonant frequency $\omega=\omega_{0}$, the converter can only operate in mode 1 when $\delta=\pi$, i.e. with full square wave operation, since the phaseshift angle cannot exceed $180^{\circ}$.

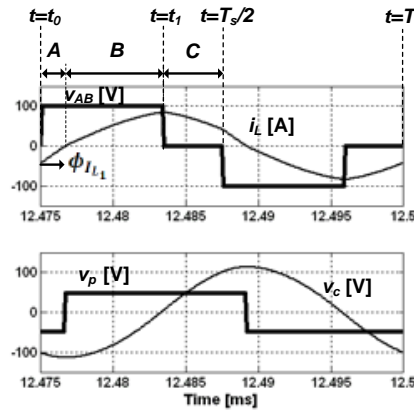

(a)
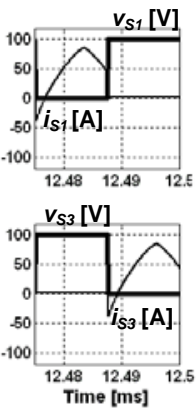
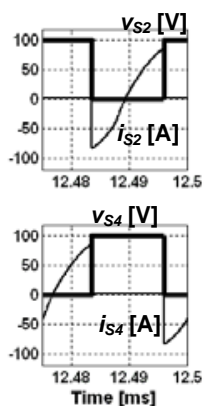

(b)

Figure 6: Mode 1 operation waveforms (all currents multiplied by 10).

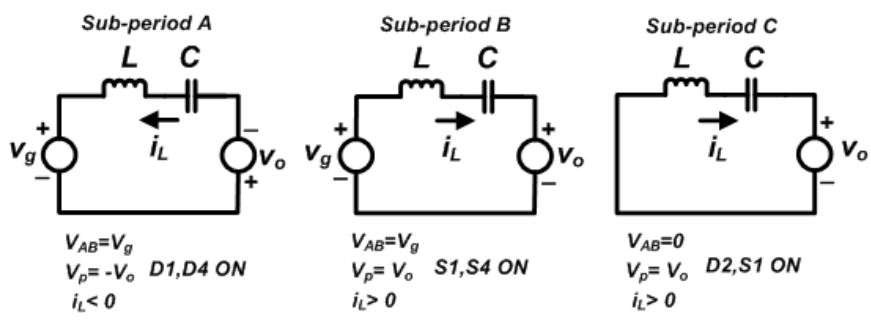

Figure 7: Equivalent circuits for positive half cycle sub-periods A-C.

\subsection{Mode 2 operation (Continuous inductor current with no energy recovery to supply)}

Typical mode 2 waveforms are shown in figure 8 . This is a continuous current mode of operation. From figure 8a, the cycle starts with powering energy transferred from the source to the tank through switches $\mathrm{S}_{1} \mathrm{~S}_{4}$ (sub-period $B$ ). Energy in the resonant tank is then dissipated during sub-period $C$ in the zero voltage loop created by $D_{2} S_{1}$. No energy is returned to the supply. The resonant inductor then reverses and continues circulating in the same zero voltage loop but in the complementary switches $\mathrm{D}_{1} \mathrm{~S}_{2}$ (sub-period $D$ shown in figure 
10). Again, no energy is recovered to supply. From figure 8b, the inverter lagging leg switches turn on at zero voltage and turn-off inductor current at $t=t_{1}$. It behaves in a similar manner as the lagging leg in mode 1 . The inverter leading leg switches, however, turn-on the positive current at $t=t_{0}$ and turn-off with negative current at $t=\frac{T_{S}}{2}$. The negative turn-off current in $S_{1}$ (through $D_{1} S_{2}$, sub-period $D$ ) flows through $S_{2} S_{3}$ at the start of the powering stage in the negative half cycle. The reverse recovery time of $D_{1}$ must be short to prevent overlapping conduction with $\mathrm{S}_{3}$ in the same leg. The same transition occurs from $D_{3}$ to $S_{1}$ at the end of the negative half cycle. This necessitates the use of fast recovery free-wheel diodes for the leading leg switches in mode 2.

In a similar manner to the analysis in mode 1 , in order to verify the converter voltage gain formula in (3), simulation results in figure 8 are taken for $\delta=90^{\circ}, Q=1, f_{s}=30 \mathrm{kHz}$ and $v_{g}=100 \mathrm{~V}$. By substituting in (3), converter voltage gain is $M=0.707$ and therefore, $v_{o} \simeq 70.7 \mathrm{~V}$. This value of $v_{o}$ can be verified from figure 8 a since $v_{p} \simeq \pm 70 \mathrm{~V}$.

If the fundamental inductor current leads at the $t=t_{0}$ instant, as shown in figure $8 \mathrm{a}$, then mode 2 occurs. This can be expressed as

$$
\begin{gathered}
-\phi_{V_{A B_{1}}}+\phi_{Z}<0 \\
\delta<\pi-2 \tan ^{-1} \frac{\pi^{2}}{8} Q\left[\frac{\omega}{\omega_{0}}-\frac{\omega_{0}}{\omega}\right]
\end{gathered}
$$

However, (10) does not give the only condition for the occurrence of mode 2. Excessive reduction of $\delta$ and lighter loads can lead to mode 3 operation (discontinuous mode) where sub-period $D$ current is zero. Mode 2 is differentiated from mode 3 by the existence of tank current during subperiod $D$ where it is necessary that $v_{c}>v_{o}$ to enable a rising slope in the inductor current. From figure 2

$$
\left|V_{c}\right|=\frac{\left|V_{A B_{1}}\right|}{\left|R_{a c}+j\left(X_{L}-X_{C}\right)\right|} *\left|X_{C}\right|=\frac{\frac{4 V g}{\pi} \sin \frac{\delta}{2}}{\left|1+j \frac{\pi^{2}}{8} Q\left[\frac{\omega}{\omega_{0}}-\frac{\omega_{0}}{\omega}\right]\right|} * \frac{Q \pi^{2} \omega_{0}}{8 \omega}
$$

Therefore, $v_{c}>v_{o}$ can be simplified to

$$
\frac{Q \pi \omega_{0}}{2 \omega}>1
$$

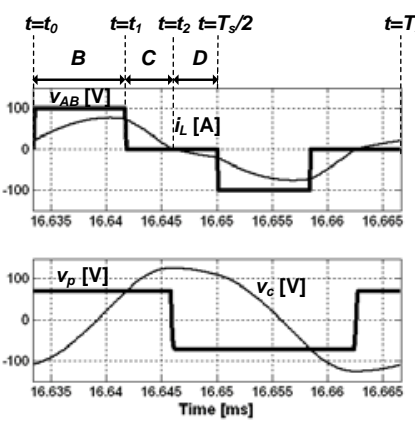

(a)

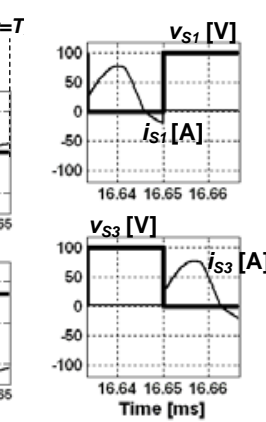

Time [ms]
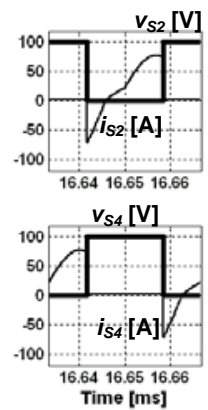

(b)

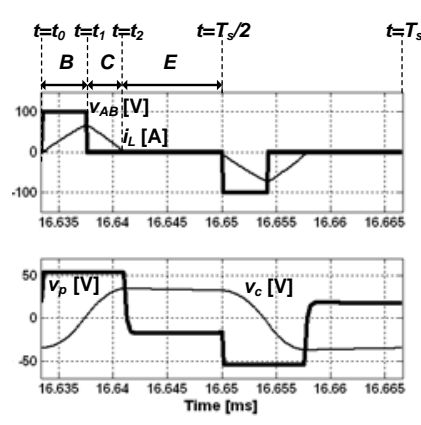

(a)

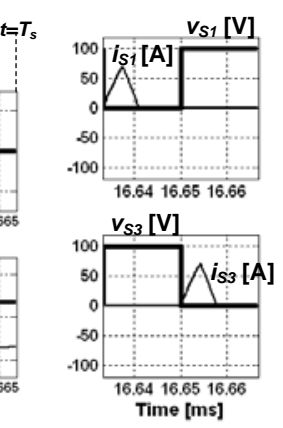

(b)

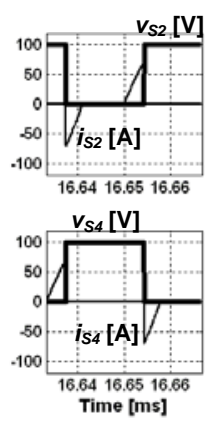

Figure 9: Mode 3 operation waveforms (all currents multiplied by 30).
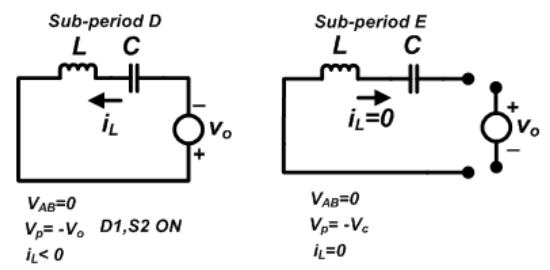

Figure 10: Equivalent circuits for positive half cycle sub-periods D-E.

Mode 2 is characterised by the existence of both conditions (10) and (12).

\subsection{Mode 3 operation (Discontinuous inductor current)}

Typical mode 3 waveforms are shown in figure 9. This is a discontinuous current mode of operation. In figure 9a, the powering stage starts at $t=t_{0}$ with sub-period $B$ where energy is transferred from the source to the tank through switches $\mathrm{S}_{1} \mathrm{~S}_{4}$. Energy is dissipated in the zero voltage loop of sub-period $C$ starting at $t=t_{1}$ and ending at $t=t_{2}$. No energy from the resonant tank is recovered in to the supply. At $t=t_{2}$, resonant tank current is zero and $v_{p}=-v_{c}$ during sub-period $E$, (figure 10) maintaining zero current until the negative half cycle powering stage starts at $t=\frac{T_{S}}{2}$. All four inverter switches have zero turn-on losses due to the zero current switching feature of this mode. Zero turn-off losses of the leading inverter leg switches occur whereas the inverter lagging leg switches turn off the positive inductor current at $t=t_{1}$.

At $t=t_{2}$ if $v_{c}>v_{o}$, inductor current would continue rising negatively. Therefore, the condition necessary for the inductor current to remain zero during sub-period $E$ is $v_{c} \leq v_{o}$. This characterizes mode 3 operation as in (13).

$$
\frac{Q \pi \omega_{0}}{2 \omega} \leq 1
$$

\section{Analysis and discussion}

Graphical analysis of the SRC is performed to give insight into converter operation. Three main variables determine the converter operational mode; phase-shift $(\delta)$, normalised frequency $\left(\omega / \omega_{0}\right)$ and quality factor $(Q)$. The effect of change in these parameters on transition from one mode to another and also on maximum power transfer to load, is investigated. 


\subsection{Mode boundaries}

Inequality (8) outlines the condition necessary for the occurrence of mode 1 . Two variables, $\omega / \omega_{0}$ and $Q$, are varied independently and the resultant $\delta$ is calculated. The resulting plane is illustrated in figure 11a with the region above it satisfying (8), i.e. mode 1 operation. The region below the plane characterizes modes 2 and 3 . The conditions stated in (12) and (13) provide the boundary between modes 2 and 3. This relation is independent of phase-shift angle $\delta$. Figure 11a shows that higher duty ratios are needed at low $Q$ factors to ensure continuous current operation (mode 1) compared to those at high $Q$ factors. The system is more likely to be in a discontinuous mode under light load conditions. It can also be seen in figure 11a that it is more likely for the converter to operate in mode 1 at higher frequencies. Much higher duty ratios are needed at lower frequencies to ensure long conduction periods, hence current continuity. Figure $11 \mathrm{~b}$ shows that in order to obtain a converter voltage gain of $M=0.4$ at a specific frequency, $\omega / \omega_{0}=1.5$, the converter traverses the three modes of operation. This depends on the loading factor $Q$; with light loads low duty ratios are needed and the converter operates in mode 3. As the loading increases, higher duty ratios are needed to obtain the same gain and the converter operates in mode 1 passing through mode 2 .

\subsection{Maximum power transfer}

Maximum power transfer occurs when the load impedance matches the resonant tank impedance [10]. With fixed resonant tank values of $L$ and $C$, the impedance varies with frequency. Considering the SRC equivalent circuit in figure 2, the condition for maximum power transfer can be expressed as

$$
\left|R_{a c}\right|=\left|X_{L}-X_{C}\right|
$$

This can be re-formulated into

$$
Q=\frac{8}{\pi^{2}\left(\frac{\omega}{\omega_{0}}-\frac{\omega_{0}}{\omega}\right)}
$$

From (15) it can be seen that for every switching frequency, there exists a value of load resistance $R_{L}$, and hence $Q$, where maximum power transfer occurs. Output power is illustrated in figure 12a for a fixed $\delta$ with variable $\omega / \omega_{0}$ and $Q$. For frequencies close to resonance the tank impedance is almost zero (purely resistive). This means a low resistive load is needed and the $Q$ for maximum power transfer is high. Converter is operating at almost full-load, hence output power is large. As the frequency increases, the tank impedance increases and maximum power occurs at lower $Q$ factors. Maximum output power is low due to operation at lighter loads. Figure $12 \mathrm{~b}$ shows the effect of changing $\delta$ on maximum power transfer. It can be seen that for a given frequency, the value of $Q$ for maximum power transfer is constant with $\delta$. In other words, the value of $Q$ for maximum power transfer is independent of $\delta$ which is what (15) proves.
The value of $\delta$ only affects the output power; the lower is the phase-shift angle $\delta$, the lower is the output power. This is logical as the converter output voltage is reduced as $\delta$ decreases.

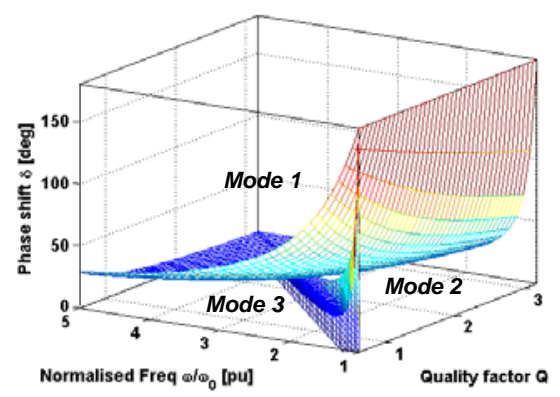

(a)

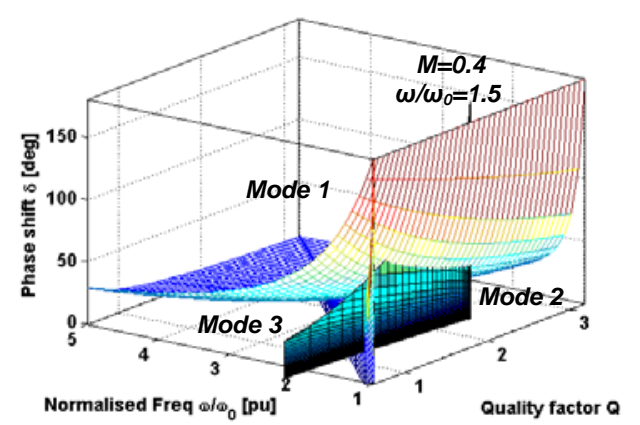

(b)

Figure 11: Mode boundaries

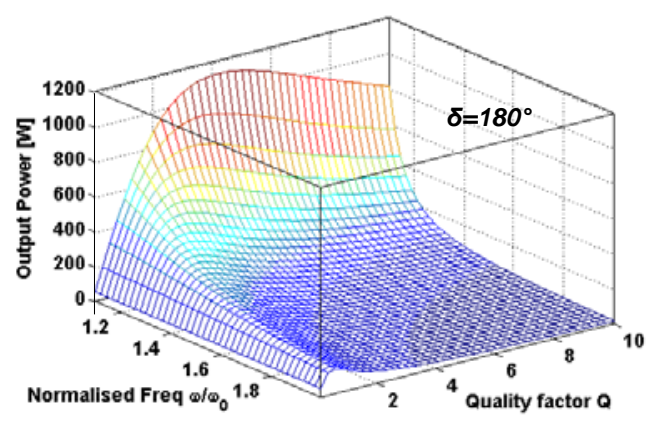

(a)

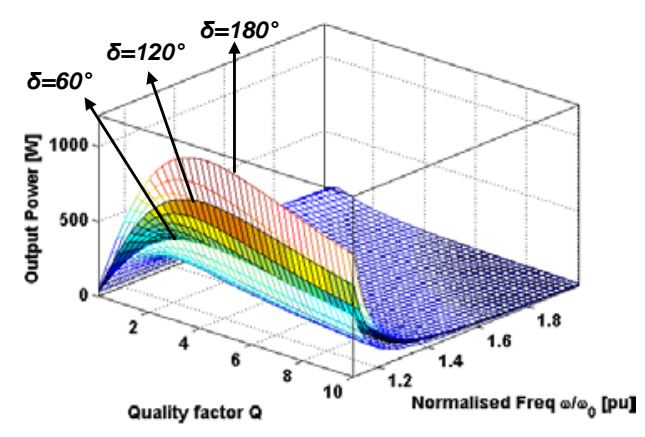

(b)

Figure 12: Maximum power transfer 


\section{Conclusion}

A generalised voltage gain transfer function for the phaseshifted SRC has been derived. The expression is a function of three variables; phase-shift, normalised frequency, and quality factor. Simulation results verified the transfer function which provided an acceptable approximation of the converter gain $(M)$. Three modes of SRC operation were investigated and their operational behaviour analysed. The switching stresses for each mode were studied. Mode 1 is clearly the preferred operating region. Conditions for the existence of each mode have been analytically derived and mode boundaries were illustrated and discussed. The converter can have the same voltage gain whilst operating in all modes depending on the loading condition. Maximum power transfer to the load was finally studied. Higher output power is achieved at frequencies closer to resonance with high $Q$ factor.

\section{References}

[1] F. C. Schwarz. "An improved method of resonant current pulse modulation for power converters”, PESC, pp. 194-204, (1975).

[2] R. R. Robson. "Advancement in series resonant inverter technology and its effect on spacecraft employing electric propulsion”, AIAA/JSASS/DGLR $16^{\text {th }}$ International Electric Propulsion Conference, pp. 1-4, (1982).

[3] V. T. Ranganathan, P. D. Ziogas and V. R Stefanovic. "A regulated dc-dc voltage source converter using a high frequency link", IEEE Trans. on industrial electronics, volume 18, no.3, pp. 279-287, (1982).

[4] R. J. King and T. A. Stuart. "Inherent overload protection for the series resonant converter", IEEE Trans. on Aerospace Electronic Systems, volume 19, no. 6, pp. 820-830, (1983).

[5] R. Oruganti and F. C. Lee. "Resonant power processors, Part II-methods of control", IEEE Trans. on industry applications, volume 21, no.6 , pp. 1461-1471, (1985).

[6] R. Oruganti, J. J. Yang and F. C. Lee. "Implementation of optimal trajectory control of series resonant converter", IEEE Trans. on Power Electronics, volume 3, no.3, pp. 318-327, (1988).

[7] S. Dalapati, S. Ray, S. Chaudhuri and C. Chakraborty. "Control of a series resonant converter by pulse-density modulation”, INDICON, pp. 601-604, (2004).
[8] H. Fujita and H. Akagi. "Pulse-density-modulated power control of a $4 \mathrm{~kW}, 450 \mathrm{kHz}$ voltage-source inverter for induction melting applications", IEEE Trans. on industry applications, volume 32, no. 2, pp. 279-286, (1996).

[9] O. Lucia, J.M. Burdio, I. Millan and J. Acero. "Loadadaptive control algorithm of half-bridge series resonant inverter for domestic induction heating", IEEE Trans. on industrial electronics, volume 56, no. 8, pp. 3106-3116, (2009).

[10] B. S. Nathan and V. Ramanarayanan. "Analysis, simulation and design of series resonant converter for high voltage applications”, ICIT, pp. 688-693, (2000).

[11] Y. Lu, K.W.E Cheng, S.L. Ho and J.F. Pan. "Passivitybased control of a phase-shifted resonant converter", IEE Proceedings-Electric Power Applications, volume 152, issue 6, pp. 1509-1515, (2005).

[12] Y. Lu, K.W.E Cheng and S.L. Ho. "Quasi current mode control for the phase-shifted series resonant converter", IEEE Trans. on Power electronics, volume 23, no. 1, pp. 353-357, (2008).

[13] Z. Ye, P.K. Jain and P.C. Sen. "A full-bridge resonant inverter with modified phase-shift modulation for high frequency ac power distribution systems", IEEE Trans. on industrial electronics, volume 54, no. 5, pp. 2831-2845, (2007).

[14] F. Tsai, P. Materu and F.C. Lee. " Constant-frequency clamped-mode resonant converters”, IEEE Trans. on power electronics, volume 3, no. 4, pp. 460-473, (1988).

[15] R. J. King and T.A. Stuart. "A normalised model for the half-bridge series resonant converter", IEEE Trans. on Aerospace and Electronic Systems, volume 17, no.2, pp. 190198, (1981).

[16] R.J.King and T.A.Stuart. "Modelling the full-bridge series-resonant power converter", IEEE Trans. on Aerospace and Electronic Systems, volume 18, no.4, pp. 449-459, (1982).

[17] R.J. King, T.A. Stuart. "Small signal model of the series resonant converters", IEEE trans. on Aerospace Electronics System, volume 21, no.3, pp. 301-319, (1985).

[18] C.Q. Lee and K. Siri. "Analysis and design of series resonant converter by state-plane Diagram", IEEE Trans. on Aerospace and Electronic Systems, volume 22, no.6, pp. 757763, (1986).

[19] Robert L. Steigerwald. "A comparison of half-bridge resonant converter topologies", IEEE Trans. on Power Electronics, volume 3, no.2, pp. 174-182, (1988). 